\title{
IS THERE A RELATIONSHIP BETWEEN SYSTEMIC PERFUSION TEMPERATURE DURING CORONARY ARTERY BYPASS GRAFTING AND EXTENT OF INTRAOPERATIVE ISCHEMIC CENTRAL NERVOUS SYSTEM INJURY?
}

Richard M. Engelman, MD

A. Bernard Pleet, $\mathrm{MD}^{\mathrm{b}}$

Richard Hicks, $\mathrm{MD}^{\mathrm{c}}$

John A. Rousou, MD

Joseph E. Flack III, MDa

David W. Deaton, MD

Penelope S. Pekow, $\mathrm{PhD}^{\mathrm{d}}$

Cheryl A. Gregory, $\mathrm{RN}^{\mathrm{a}}$
Objective: This study was designed to compare the volume of cerebral infarction in patients operated on under either hypothermic or tepid/normothermic perfusion for coronary revascularization. Methods: A randomized trial with preoperative, postoperative, and late neurologic evaluation was conducted in patients undergoing coronary revascularization having either hypothermic or tepid/normothermic perfusion for coronary revascularization. The goal was to determine whether perfusion temperature correlated with neurologic dysfunction associated with coronary artery bypass. Results: Twelve intraoperative ischemic strokes occurred during coronary revascularization in a series of 291 patients. Six of these were in the group receiving hypothermic perfusion and 6 in groups receiving the tepid/normothermic perfusion. Measuring the infarct volume documented that 3 of the strokes in each group resulted in minor or small infarcts and 3 in each group were significant, major strokes. The volume of infarction, whether including all 6 patients in each group or only those with major strokes, was no different between the hypothermic and the tepid/normothermic groups. Conclusions: In this series of 291 patients randomized to perfusion temperature, we observed no relationship between the size of a cerebral ischemic infarct and the perfusate temperature during coronary revascularization. (J Thorac Cardiovasc Surg 2000;119:230-2)
$\mathrm{T}^{1}$ he impetus for this report is an article from Catholic University in Rome describing the increased severity of intraoperative cerebral injury associated with normothermic cardiopulmonary bypass (CPB). ${ }^{1}$ Our group recently completed a National Institutes of Health trial of normothermic versus hypothermic perfusion for coronary revascularization, and we duplicated the approach used in the aforementioned study to measure the volume of infarct size based on computed tomo-

From the Departments of Surgery (Cardiac Surgery Division), ${ }^{\mathrm{a}}$ Medicine (Neurology Division), ${ }^{\mathrm{b}}$ and Radiology, ${ }^{\mathrm{c}}$ Baystate Medical Center, Springfield, Mass; and the Department of Biostatistics and Epidemiology, ${ }^{\mathrm{d}}$ School of Public Health and Health Sciences, University of Massachusetts, Amherst, Mass. Supported by National Institutes of Health grant 1R01 HL-48631.

Received for publication May 14, 1999; revisions requested Sept 7, 1999; revisions received Sept 23, 1999; accepted for publication Sept 28, 1999.

Address for reprints: Richard Engelman, MD, Division of Cardiac Surgery, Baystate Medical Center, 759 Chestnut St, Springfield, MA 01107 (E-mail: richard.engelman@bhs.org).

Copyright $\odot 2000$ by Mosby, Inc.

$0022-5223 / 2000 \$ 12.00+0 \quad \mathbf{1 2 / 1 / 1 0 3 2 9 5}$ graphic (CT) analysis. This provides a report comparable with that presented by Gaudino and associates. ${ }^{1}$

\section{Methods}

A study was designed in 1992 to compare 3 perfusion temperatures, cold $\left(20^{\circ} \mathrm{C}\right)$, tepid $\left(32^{\circ} \mathrm{C}\right)$, and warm $\left(37^{\circ} \mathrm{C}\right)$, for $\mathrm{CPB}$ during coronary revascularization in a prospective randomized manner to study the neurologic sequelae of hypothermic versus normothermic perfusion. The patients in this study had either elective or urgent operations and required 3 or more grafts, thus ensuring at least a 60-minute CPB time. As in the Gaudino publication, ${ }^{1}$ these patients were all in a "low risk category" for neurologic injury, limiting age to less than 76 years and having no prior neurologic history. Other exclusion criteria were poor left ventricular function (ejection fraction $<30 \%$ ), ongoing myocardial ischemia necessitating an intra-aortic balloon, renal dysfunction with a serum creatinine level more than $2.0 \mathrm{mg} / \mathrm{L}$, or recent ( $<7$ days) postinfarction angina and carotid stenosis of more than $70 \%$ by duplex scan. Randomization took place in the operating room immediately before the operation by choosing the temperature from a sealed envelope. The study was approved March 4, 1993, by the Institutional Review Board of Baystate Medical Center.

The first patient was enrolled on February 7, 1994, and the trial was completed on December 4, 1997, a study period just 
short of 4 years. A total of 291 patients were enrolled. A detailed neurologic evaluation was performed before the operation, 3 to 4 days after the operation (before discharge), and at 1 month when returning for a postoperative visit. Whenever the neurologist detected an abnormality suggestive of a stroke, a cerebral CT scan was performed. This was accomplished in 49 patients.

The intent of this study was to see whether any relationship exists between the perfusion temperature and the size of an intraoperative cerebral infarction. The method for measuring the volume of infarct is the same as that used in the Gaudino paper, ${ }^{1}$ which was validated in 2 prior publications by Petersen and associates. ${ }^{2,3}$ This approach entails measuring the width and length of the lesion on the axial CT slice, multiplying the 2 measurements, and then multiplying the result by the thickness of the CT slice $(10 \mathrm{~mm})$. When lesions appeared on multiple views, the volume of each was added to obtain the total volume of infarction.

Method of anesthesia. Anesthesia was used in a consistent manner across all temperature groups: premedication with lorazepam (1-2 mg orally); induction with fentanyl (5-15 $\mu \mathrm{g} / \mathrm{kg}$ intravenously), midazolam ( $0.05 \mathrm{mg} / \mathrm{kg}$ intravenously), and pancuronium $(0.15 \mathrm{mg} / \mathrm{kg}$ intravenously); and maintenance with fentanyl ( $<10 \mu \mathrm{g} / \mathrm{kg}$ intravenously), and isoflurane titrated as tolerated (usually $0.5 \%-1.0 \%$ ). The patient was extubated as expeditiously as possible consistent with patient safety. Although no medication was given after the operation to maintain paralysis, no patients had reversal of pancuronium. In patients who were hypothermic and shivering after the operation, medication was administered to facilitate a comfortable recovery. Fast-track extubation and recovery were attempted in every patient. ${ }^{4}$

Method of CPB. A Cobe roller pump (Cobe Cardiovascular Inc, Arvada, Colo) and the Affinity hollow-fiber membrane oxygenator (Avecor Cardiovascular Inc, Plymouth, Minn) were used for CPB. Heparin bonding was not used in the perfusion tubing or oxygenator. An 8-mm Sarns aortic arch cannula (Sarns/3M Health Care, Ann Arbor, Mich) or a 20F DLP arterial cannula (DLP Inc, Grand Rapids, Mich) was used for aortic cannulation and a 36F dual-drainage single venous catheter from Research Medical (Midvale, Utah) was used for venous return. A DLP Gundry RCSP $15 \mathrm{~F}$ coronary sinus catheter was used for retrograde cardioplegia. The volume of CPB perfusate was $2 \mathrm{~L} \cdot \mathrm{min}^{-1} \mathrm{~m}^{-2}$ body surface area or more in patients receiving $20^{\circ} \mathrm{C}$ perfusion and near 3 $\mathrm{L} \cdot \mathrm{min}^{-1} \mathrm{~m}^{-2}$ body surface area for patients receiving $32^{\circ} \mathrm{C}$ or $37^{\circ} \mathrm{C}$ perfusion. Venous saturation was maintained at more than $70 \%$, and mean perfusion pressure was regulated to 60 to $80 \mathrm{~mm} \mathrm{Hg}$ by use of phenylephrine for vasoconstriction and isoflurane for vasodilation. The hematocrit value was maintained at $20 \%$ or more during perfusion and at $22 \%$ or more during recovery. Activated clotting times and heparin levels were monitored before $\mathrm{CPB}$ and every 30 minutes during CPB. The initial heparin dose was $500 \mathrm{U} / \mathrm{kg}$, given intravenously, and additional heparin was given if the activated clotting time was less than 600 seconds or the heparin level was less than $3 \mathrm{mg} / \mathrm{kg}$. The $\mathrm{pH}$ regulation throughout the operation was maintained by alpha-stat management. Antifibrinolytic agents, including aminocaproic acid (Amicar) and aprotinin, were not administered in this study.

The perfusate temperature used in this study was the only difference among the 3 groups. In the normothermic group, perfusate temperature was maintained at $37^{\circ} \mathrm{C}$ and no higher. In the hypothermic group $\left(20^{\circ} \mathrm{C}\right)$, we deliberately decreased the temperature to the chosen level gradually so that a $10^{\circ} \mathrm{C}$ maximal difference existed between arterial and venous blood. Core temperature reached $35^{\circ} \mathrm{C}$ to $36^{\circ} \mathrm{C}$ in the normothermic group, $32^{\circ} \mathrm{C}$ to $33^{\circ} \mathrm{C}$ in the tepid group, and $23^{\circ} \mathrm{C}$ to $28^{\circ} \mathrm{C}$ in the hypothermic group. Cooling, when indicated, began soon after commencement of CPB and continued until arterial perfusate temperature reached either $32^{\circ} \mathrm{C}$ (soon after commencing cooling) or $20^{\circ} \mathrm{C}$ (often taking 15-30 minutes). Crossclamp application and coronary artery bypass grafting were performed immediately on initiation of CPB. Rewarming began with initiation of the last distal anastomosis, usually the left internal thoracic artery to the left anterior descending coronary artery. Again, rewarming was slow with maintenance of a $10^{\circ} \mathrm{C}$ maximal gradient between arterial and venous blood. Rewarming never exceeded a perfusate temperature of $39^{\circ} \mathrm{C}$ until 1996 and $38^{\circ} \mathrm{C}$ from 1996 to 1998 .

Operative technique. Antegrade-retrograde blood cardioplegia was used with administration into the coronary sinus and each completed vein graft for 3 of the 4 surgeons (R.M.E., J.A.R., and D.W.D.). Proximal anastomoses were performed with a side-biting clamp after unclamping. The fourth surgeon used a single crossclamp for both anastomoses, using then only retrograde cardioplegia.

Statistical analysis. The Fisher exact test was used to determine significant differences in the rate of occurrence of ischemic stroke between patient groups defined by perfusate temperature. To make the study comparable with that presented by Gaudino and associates, ${ }^{1}$ in which normothermic perfusion was defined as $34^{\circ} \mathrm{C}$ to $37^{\circ} \mathrm{C}$, we combined the tepid $\left(32^{\circ} \mathrm{C}\right)$ and normothermic $\left(37^{\circ} \mathrm{C}\right)$ groups from our study and considered them normothermic for these analyses. A 2sample $t$ test was used to compare the estimated ischemic cerebral infarct volume for the 2 groups of patients, normothermic or hypothermic $\left(20^{\circ} \mathrm{C}\right)$. Because of the small sample size and large spread of the data, a Mann-Whitney 2-sample rank sum test was also performed. Data are reported for each group as the infarct size, median, and range of values.

\section{Results}

Forty-nine patients of the 291 in the trial had the suspicion of a cerebral vascular accident (CVA) (16.8\%), and a CT scan was performed. Thirteen or $4.5 \%$ of the 291 had a documented CVA by CT scan, 4 who received warm perfusion, 3 tepid perfusion, and 6 cold perfusion. One of the patients receiving warm perfusion had a CVA related to atrial fibrillation immediately before discharge from the hospital. Although he is included as having had a CVA in the trial, it was clear- 
ly not an intraoperative event. The remaining 12 patients comprised the study group, 6 considered normothermic and 6 hypothermic.

The actual computation of infarct volume was useful since it allowed an objective measure of stroke severity. In the hypothermic patients, 3 had significant infarcts, defined as more than $300 \mathrm{~mm}^{3}$, and similarly in the normothermic series, 3 were significant. The absence of a significant infarct was associated with minimal deterioration in neurologic function and, in fact, no infarction was apparent to the patient and his or her family. Only a sophisticated neurologic evaluation uncovered an ischemic CVA. Nonsevere strokes were most often associated with lacunar or watershed infarctions.

Quantification of infarct size resulted in the following data: for the normothermic group, volumes ranged from 60 to $5630 \mathrm{~mm}^{3}$, with a median of $900 \mathrm{~mm}^{3}$. For the hypothermic group, the median was $720 \mathrm{~mm}^{3}$, with volumes ranging from 130 to $5890 \mathrm{~mm}^{3}$. If one eliminates the minor strokes from this analysis ( 3 patients from each group), then the infarct volumes are clearly larger for both groups, but there is still no significant difference in infarct volumes between the 2 temperature groups. With severe ischemic insults alone, the 2 groups remain comparable: infarct volumes of 1520 , 3260 , and $5630 \mathrm{~mm}^{3}$ were observed in the normothermic group and volumes of 1260,4390 , and $5890 \mathrm{~mm}^{3}$ in the hypothermic group.

\section{Discussion}

Substantial data exist to support the proposition that hyperthermia in the presence of acute stroke, even of a small degree, such as elevations between $37.5^{\circ} \mathrm{C}$ and $38^{\circ} \mathrm{C}$, is deleterious to central nervous system $(\mathrm{CNS})$ function, leading to an increase in infarct size. ${ }^{5}$ Indeed, a recent report documented improved neurologic function in the setting of acute traumatic brain injury associated with therapeutic hypothermia. ${ }^{6}$ Thus the concept of reducing CNS infarct size during CPB by using hypothermia has inherent appeal.

The issues, however, are by no means clear-cut. When patients are hypothermic, they must be rewarmed to discontinue $\mathrm{CPB}$, and this rewarming process may lead to cerebral hyperthermia. ${ }^{7}$ Additionally, the development of cerebral embolization is most often associated with periods when the brain is warm, such as on initiation of CPB (blast effect of blood flow) and crossclamp application and removal. ${ }^{8}$ Thus the use of deliberate hypothermia may not be advantageous but rather lead to a situation in which hyperthermia is inevitable, a consequence of the process of rewarming.

Our study was a randomized trial and for this reason holds a potential advantage over that of Gaudino and associates, ${ }^{1}$ which was a sequential analysis with the hypothermic group treated first. Our study found 12 intraoperative strokes among 291 patients whereas their analysis found 25 of 2987. However, our analysis used a sophisticated neurologic evaluation in all 291 patients, and in their study the anesthesiologist evaluated the presence of a CNS event. Thus 6 of the 12 CVAs in our analysis would have gone undetected because they were associated with no apparent CNS deficit in the opinion of both the attending surgeon and the patient. These were associated with small infarcts $\left(<300 \mathrm{~mm}^{3}\right)$ usually in the watershed or lacunar region.

The implications of the Gaudino report ${ }^{1}$ are certainly worthy of consideration, but the variability of patients and their clinical setting is such as to prevent a conclusion that normothermic perfusion is detrimental. Rather, one could conclude that maintenance of a perfusion temperature at $34^{\circ} \mathrm{C}$ to $37^{\circ} \mathrm{C}$ is most important during CPB. In fact, this is best accomplished if hypothermia is avoided completely, allowing rewarming to be accomplished without aggressive elevation of perfusion temperature.

\section{REFERENCES}

1. Gaudino M, Martinelli L, Di Lella G, et al. Superior extension of intraoperative brain damage in case of normothermic systemic perfusion during coronary artery bypass operations. J Thorac Cardiovasc Surg 1999;118:432-7.

2. Petersen P, Madsen EB, Brun B, Pedersen F, Gyldensted C, Boysen G. Silent cerebral infarction in chronic atrial fibrillation. Stroke 1987;18:1098-100.

3. Petersen P, Pedersen P, Johnsen A, et al. Cerebral computed tomography in paroxysmal atrial fibrillation. Acta Neurol Scand 1989;79:482-6.

4. Engelman RM, Rousou JA, Flack JE III, et al. Fast-track recovery of coronary bypass patients. Ann Thorac Surg 1994;58:1742-6.

5. Ginsberg MD, Busto R. Combating hyperthermia in acute stroke: a significant clinical concern. Stroke 1998;29:529-34.

6. Barbut D, Hinton BA, Szatrowski TP, et al. Cerebral emboli detected during bypass surgery are associated with clamp removal. Stroke 1994;25:2398-402.

7. Engelman RM, Pleet AB, Rousou JA, et al. The influence of CPB perfusion temperature on neurologic and hematologic function after CABG. Ann Thorac Surg 1999;67:1547-56.

8. Shaw PJ, Bates D, Carlidge NEF, et al. Neurologic and neuropsychological morbidity following major surgery: comparison of coronary artery bypass and peripheral vascular surgery. Stroke 1987;18:700-7. 